Note

\title{
Determination Method for Total Arsenic and Partial-digestion Method with Nitric Acid for Inorganic Arsenic Speciation in Several Varieties of Rice
}

\author{
(Received January 15, 2010)

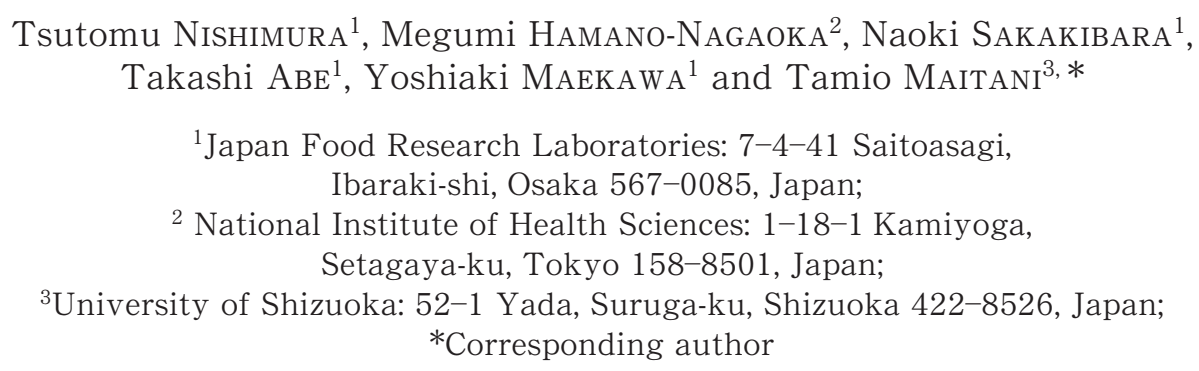

The determination method of total arsenic (As) and the speciation method of inorganic As for non-glutinous rice reported in our preceding paper were applied to several varieties of rice under optimized experimental conditions. In the determination of total As with ICP-MS, acetic acid was added to increase the sensitivity and an internal reference method with germanium was adopted to increase the precision. The extraction temperature in the partial-digestion method with nitric acid to speciate inorganic As was raised to $100^{\circ} \mathrm{C}$, because extraction efficiency over $90 \%$ was obtained from glutinous rice and colored rice at this temperature. In the investigation of polished and unpolished forms of non-glutinous, glutinous, and colored rice, the amounts of total and inorganic As were $0.04-0.54 \mathrm{mg} / \mathrm{kg}$ and $0.02-0.41 \mathrm{mg} / \mathrm{kg}$, respectively. The color of rice was not related to total or inorganic As content. These results indicate that the inorganic As content in commercial rice should be carefully monitored.

Key words: rice; glutinous rice, arsenic; inorganic arsenic; speciation; partial digestion; HPLC-ICP/MS

\section{Introduction}

Arsenic (As) is an element that may pose a health risk to humans ${ }^{1)}$. Inorganic As is known to be an initiator of carcinogenesis ${ }^{2)}$; therefore it is important to estimate the content of inorganic As in the diet. The Food and Agriculture Organization/World Health Organization (FAO/WHO) recommended a provisional tolerable weekly intake (PTWI) of $15 \mu \mathrm{g}$ of inorganic As/kg body weight. Although As consumption is mainly from seafood $^{3), 4)}$, rice contains inorganic As, and is consumed around the world, especially in Asia as a staple food. Therefore, As in rice might be associated with a risk to human health.

Many varieties of rice are cultivated around the world. In Asia, glutinous rice (MOCHIGOME) varieties cooked by steaming for rice-cake, as well as nonglutinous rice cooked by boiling, are generally consumed. Glutinous rice is stickier than non-glutinous rice, because its starch consists mainly of amylopectin, while non-glutinous rice contains amylose. Rice varieties with colored endosperm kernels such as red,

\footnotetext{
* E-mail: maitani@u-shizuoka-ken.ac.jp
}

violet-black, and green rice, considered to be of the species Oryza sativa ${ }^{5}$, are also consumed in Asia. Their kernels contain tannin, anthocyanin, and chlorophyll pigments, as well as polyphenols. Colored rice is not only consumed as a staple food in some countries but also used as a pigment and a nutritional supplementation to white rice in some Asian countries. Therefore, in the evaluation of inorganic As in rice, it is important to evaluate glutinous rice and colored rice as well as nonglutinous rice.

The determination methods of total As and inorganic As in several varieties of rice were examined in this study. It was reported that higher intensities of As were obtained in ICP-MS with the addition of carbon sources, such as methanol ${ }^{6), 7)}$. In this paper, acetic acid was used to increase the sensitivity of As.

For the accurate determination of inorganic As, a method with high extraction efficiency is required. Several extraction methods have been reported; amylolysis with enzyme, hydrolysis with $2 \mathrm{~mol} / \mathrm{L}$ trifluoroacetic acid (TFA), and microwave extraction with water ${ }^{8)-10)}$. As we have reported previously, partial digestion with nitric acid is also effective to extract inorganic As from non-glutinous rice ${ }^{11}$. In the previous paper, the extrac- 
tion temperature was set at the same level $\left(80^{\circ} \mathrm{C}\right)$ as for hijiki $^{12)}$ so that hijiki and rice could be treated simultaneously.

In this paper, the effect of extraction temperature was further studied with the aim of applying the method to various types of glutinous rice and colored rice, and the total and inorganic As levels in several varieties of rice were determined by use of the established method.

\section{Materials and Methods}

\section{Chemicals}

Arsenite solution (100 mg/L as As (III)), germanium (Ge) solution (1,000 mg/L), certified by Japan Calibration Service System (JCSS) for atomic absorption analysis, and nitric acid (Ultrapur-100) were purchased from Kanto Chemical Co., Inc. (Tokyo, Japan). Monomethylarsonic acid (MMA) and dimethylarsinic acid (DMA) were purchased from Tri Chemical Laboratories Inc. (Yamanashi, Japan). Other chemicals used were of trace element analysis grade.

\section{Sample preparation}

All of the brown or polished rice samples were purchased from a commercial retailer or an internet shop in Japan. Some brown rice samples were polished in a rice polishing machine (KG-11, Panasonic, Osaka, Japan) 2 or 3 times, until no further bran could be removed. Polished rice was ground in a food mill (Labo Milser LM-PLUS, Iwatani Corporation, Tokyo, Japan) to a particle size of less than $0.5 \mathrm{~mm}$.

\section{Digestion for total As determination}

Approximately $0.5 \mathrm{~g}$ of each sample was weighed precisely into a PTFE digestion vessel, then $5 \mathrm{~mL}$ of nitric acid and $1 \mathrm{~mL}$ of hydrogen peroxide were added, and the mixture was left to stand in a ventilated enclosure until the initial reaction subsided. The vessels were closed with PTFE covers and digestion was performed with a microwave digestion system (ETHOS, Milestone, CT, U.S.A.). The microwave digestion program was as follows: the first step was 2 min to $70^{\circ} \mathrm{C}$ at $1,000 \mathrm{~W}$; the second step was $5 \mathrm{~min}$ at $50^{\circ} \mathrm{C}$ to $0 \mathrm{~W}$; the third step was $20 \mathrm{~min}$ to $200^{\circ} \mathrm{C}$ at $1,000 \mathrm{~W}$; the fourth step was $30 \mathrm{~min}$ at $200^{\circ} \mathrm{C}$ at $1,000 \mathrm{~W}$. The vessel was opened after cooling, and water was added to the digested solution. Subsequently $1 \mathrm{~mL}$ of acetic acid and $1 \mu \mathrm{g}$ of $\mathrm{Ge}$, as an internal standard solution, were added. The solution was transferred to a PP tube and made up to $50 \mathrm{~mL}$ with water.

\section{Total As determination}

Total As in the digested solution was determined using an ICP-MS machine (Agilent 7500ce, Agilent Technologies, CA, U.S.A.) in the helium collision mode to decompose $\mathrm{ArCl}$ interfering ion at $\mathrm{m} / z$ 75. The analytical conditions were: RF power, $1.6 \mathrm{~kW}$; plasma gas, $15 \mathrm{~L} / \mathrm{min}$; carrier gas, $0.70 \mathrm{~L} / \mathrm{min}$; auxiliary gas, $0.90 \mathrm{~L} / \mathrm{min}$; makeup gas, $0.43 \mathrm{~L} / \mathrm{min}$. The peak intensities at $m / z 75$ and 72 for As and Ge, respectively, were measured, and As concentration was calculated from the intensity ratio of As to Ge in each solution by the internal reference method.

\section{Extraction of inorganic As from rice}

Approximately $0.5 \mathrm{~g}$ of each sample was weighed precisely into a digestion tube, and $2 \mathrm{~mL}$ of $0.15 \mathrm{~mol} / \mathrm{L}$ nitric acid was added. A glass cover was put in place to avoid evaporation of the solvent, and heating was carried out at $100^{\circ} \mathrm{C}$ for 2 hours in an aluminum heating block. The extract was made up to $10 \mathrm{~mL}$ with water and centrifuged at 3,500 rpm. The supernatant was transferred to a PP tube as the sample solution.

\section{Speciation of As}

To determine inorganic As, speciation analyses of As(III), As(V), MMA, and DMA were carried out with an HPLC apparatus (Agilent 1200 Series, Agilent Technologies, CA, U.S.A) coupled with an ICP-MS machine (Agilent 7500ce, Agilent Technologies, CA, U.S.A.). The analytical conditions were reported previously ${ }^{11)}$. The As concentration was determined from the As peak area.

\section{Results and Discussion}

\section{Determination of total As}

In evaluating a method for the determination of inorganic As in rice, the accuracy of determination of the total As content is also important, because extraction efficiency is evaluated as the ratio of extracted As to total As. To determine total As by ICP-MS, the internal reference method or the standard addition method can be used ${ }^{13)}$. The standard addition method is able to correct interference from the matrix; however, the number of measurements is greater. The internal reference method may be employed if an element similar to the internal standard is not included in the sample. Although ICP-MS is a highly sensitive method, the intensity depends on the mass number due to spacecharge effects ${ }^{14)}$. Therefore, in this study, Ge was used as the internal reference element in the determination of total As, because its mass number is close to that of As. To increase the sensitivity, acetic acid was added.

The ICP-MS intensity of As with the addition of acetic acid was approximately 2.8-fold higher than that without acetic acid (Table 1). The limit of detection

Table 1. Effects of addition of acetic acid on the peak intensity of As (cps)

\begin{tabular}{ccc}
\hline \hline \multirow{2}{*}{$\begin{array}{c}\text { Concentration of As solution } \\
(\mu \mathrm{g} / \mathrm{L})\end{array}$} & \multicolumn{2}{c}{ Acetic acid } \\
\cline { 2 - 3 } & Added & Not added \\
\hline 0 & 4 & 1 \\
0.2 & 211 & 76 \\
0.5 & 493 & 178 \\
1.0 & 905 & 341 \\
2.5 & 2,530 & 891 \\
5.0 & 4,604 & 1,631 \\
10.0 & 9,134 & 3,296 \\
\hline
\end{tabular}


Table 2. Comparison of extraction efficiency between white and colored rice

\begin{tabular}{|c|c|c|c|c|c|c|}
\hline \multirow{2}{*}{ Grain color } & \multirow{2}{*}{ Type } & \multirow{2}{*}{ Total As (mg/kg) } & \multicolumn{2}{|c|}{ Total As in extract $(\mathrm{mg} / \mathrm{kg})$} & \multicolumn{2}{|c|}{ Extraction efficiency $(\%)^{*}$} \\
\hline & & & $80^{\circ} \mathrm{C}$ & $100^{\circ} \mathrm{C}$ & $80^{\circ} \mathrm{C}$ & $100^{\circ} \mathrm{C}$ \\
\hline White (unpolished) & Glutinous & $0.54 \pm 0.024$ & $0.40 \pm 0.003$ & $0.49 \pm 0.013$ & 74 & 91 \\
\hline White (polished) & Glutinous & $0.29 \pm 0.007$ & $0.24 \pm 0.002$ & $0.26 \pm 0.002$ & 83 & 90 \\
\hline White (polished) & Jasmine & $0.10 \pm 0.001$ & $0.08 \pm 0.005$ & $0.10 \pm 0.007$ & 80 & 100 \\
\hline Violet-black (unpolished) & Glutinous & $0.42 \pm 0.008$ & $0.33 \pm 0.017$ & $0.39 \pm 0.016$ & 79 & 93 \\
\hline NIST1568a\# (brown flour) & Not described & $0.32 \pm 0.011$ & $0.30 \pm 0.007$ & $0.31 \pm 0.004$ & 94 & 97 \\
\hline
\end{tabular}

Mean \pm SD (3 determinations)

* Extracted total As concentration/total As concentration

\# Certified value is $0.29 \pm 0.03 \mathrm{mg} / \mathrm{kg}$

Table 3. Comparison of speciation at two extraction temperatures

\begin{tabular}{|c|c|c|c|c|c|c|c|c|c|c|}
\hline \multirow{2}{*}{ Sample } & \multicolumn{2}{|c|}{$\mathrm{As}(\mathrm{III})$} & \multicolumn{2}{|c|}{$\mathrm{As}(\mathrm{V})$} & \multicolumn{2}{|c|}{$\begin{array}{c}\text { Inorganic As } \\
(\mathrm{As}(\mathrm{III})+\mathrm{As}(\mathrm{V}))\end{array}$} & \multicolumn{2}{|c|}{ MMA } & \multicolumn{2}{|c|}{ DMA } \\
\hline & $80^{\circ} \mathrm{C}$ & $100^{\circ} \mathrm{C}$ & $80^{\circ} \mathrm{C}$ & $100^{\circ} \mathrm{C}$ & $80^{\circ} \mathrm{C}$ & $100^{\circ} \mathrm{C}$ & $80^{\circ} \mathrm{C}$ & $100^{\circ} \mathrm{C}$ & $80^{\circ} \mathrm{C}$ & $100^{\circ} \mathrm{C}$ \\
\hline $\begin{array}{l}\text { Brown } \\
\text { rice }\end{array}$ & $0.306 \pm 0.002$ & $0.397 \pm 0.003$ & $0.019 \pm 0.003$ & $0.015 \pm 0.002$ & $0.325 \pm 0.005$ & $0.412 \pm 0.003$ & $<0.008$ & $<0.008$ & $0.079 \pm 0.002$ & $0.088 \pm 0.005$ \\
\hline $\begin{array}{l}\text { NIST } \\
1568 \mathrm{a}\end{array}$ & $0.057 \pm 0.004$ & $0.069 \pm 0.001$ & $0.027 \pm 0.003$ & $0.022 \pm 0.001$ & $0.084 \pm 0.005$ & $0.091 \pm 0.006$ & $0.010 \pm 0.001$ & $0.009 \pm 0.002$ & $0.154 \pm 0.004$ & $0.171 \pm 0.008$ \\
\hline
\end{tabular}

Mean \pm SD (5 determinations)

$(\mathrm{mg} / \mathrm{kg})$

Table 4. Speciation of As in several varieties of rice

\begin{tabular}{|c|c|c|c|c|c|c|c|c|c|c|}
\hline Color & Grain type & $\begin{array}{c}\text { Starch } \\
\text { type*, } \\
\text { Process** }\end{array}$ & Origin & $\begin{array}{c}\mathrm{As}(\mathrm{III}) \\
(\mathrm{mg} / \mathrm{kg})\end{array}$ & $\begin{array}{c}\mathrm{As}(\mathrm{V}) \\
(\mathrm{mg} / \mathrm{kg})\end{array}$ & $\begin{array}{l}\text { MMA } \\
(\mathrm{mg} / \mathrm{kg})\end{array}$ & $\begin{array}{c}\text { DMA } \\
(\mathrm{mg} / \mathrm{kg})\end{array}$ & $\begin{array}{c}\text { Inorganic } \\
\mathrm{As}^{\#}(\mathrm{mg} / \mathrm{kg})\end{array}$ & $\begin{array}{l}\text { Total As } \\
(\mathrm{mg} / \mathrm{kg})\end{array}$ & $\begin{array}{c}\text { Inorganic } \\
\text { As/Total } \\
\text { As (\%) }\end{array}$ \\
\hline White & Short & $N G, P$ & Italy & $0.052 \pm 0.003$ & $<0.008$ & $<0.008$ & $0.026 \pm 0.001$ & $0.05 \pm 0.003$ & $0.09 \pm 0.003$ & 56 \\
\hline White & Short & $N G, P$ & Spain & $0.041 \pm 0.004$ & $<0.008$ & $<0.008$ & $0.009 \pm 0.001$ & $0.04 \pm 0.004$ & $0.05 \pm 0.004$ & 80 \\
\hline White & Short & NG, P & China & $0.078 \pm 0.001$ & $<0.008$ & $<0.008$ & $0.019 \pm 0.001$ & $0.08 \pm 0.006$ & $0.10 \pm 0.004$ & 80 \\
\hline White & Short & $\mathrm{NG}, \mathrm{P}$ & Japan & $0.191 \pm 0.019$ & $<0.008$ & $<0.008$ & $0.098 \pm 0.006$ & $0.20 \pm 0.016$ & $0.34 \pm 0.010$ & 59 \\
\hline White & Short & NG, P & Japan & $0.120 \pm 0.004$ & $<0.008$ & $<0.008$ & $0.012 \pm 0.001$ & $0.12 \pm 0.004$ & $0.10 \pm 0.010$ & 120 \\
\hline White & Short & NG, NP & Japan & $0.251 \pm 0.022$ & $0.009 \pm 0.003$ & $<0.008$ & $0.043 \pm 0.002$ & $0.26 \pm 0.018$ & $0.32 \pm 0.006$ & 81 \\
\hline White & Short & NG, NP & Japan & $0.123 \pm 0.002$ & $<0.008$ & $<0.008$ & $<0.008$ & $0.12 \pm 0.002$ & $0.11 \pm 0.005$ & 109 \\
\hline White & Short & NG, NP & Japan & $0.107 \pm 0.003$ & $<0.008$ & $<0.008$ & $<0.008$ & $0.11 \pm 0.003$ & $0.14 \pm 0.005$ & 79 \\
\hline White & Short & NG, NP & Japan & $0.257 \pm 0.007$ & $<0.008$ & $<0.008$ & $0.023 \pm 0.003$ & $0.26 \pm 0.007$ & $0.27 \pm 0.005$ & 96 \\
\hline White & Short & $\mathrm{G}, \mathrm{NP}$ & Japan & $0.397 \pm 0.003$ & $0.015 \pm 0.002$ & $<0.008$ & $0.088 \pm 0.005$ & $0.41 \pm 0.003$ & $0.54 \pm 0.024$ & 76 \\
\hline White & Short & $\mathrm{G}, \mathrm{NP}$ & Japan & $0.114 \pm 0.003$ & $<0.008$ & $<0.008$ & $<0.008$ & $0.11 \pm 0.003$ & $0.11 \pm 0.004$ & 100 \\
\hline White & Short & $\mathrm{G}, \mathrm{P}$ & Japan & $0.078 \pm 0.003$ & $<0.008$ & $<0.008$ & $0.023 \pm 0.002$ & $0.08 \pm 0.003$ & $0.10 \pm 0.004$ & 80 \\
\hline White & Short & $\mathrm{G}, \mathrm{P}$ & Japan & $0.088 \pm 0.002$ & $<0.008$ & $<0.008$ & $0.021 \pm 0.002$ & $0.09 \pm 0.002$ & $0.10 \pm 0.001$ & 90 \\
\hline White & Short & $G, P$ & U.S.A. & $0.073 \pm 0.003$ & $<0.008$ & $<0.008$ & $0.012 \pm 0.001$ & $0.07 \pm 0.003$ & $0.07 \pm 0.002$ & 100 \\
\hline White & Medium & NG, P & U.S.A. & $0.058 \pm 0.002$ & $<0.008$ & $<0.008$ & $0.028 \pm 0.001$ & $0.06 \pm 0.002$ & $0.09 \pm 0.004$ & 67 \\
\hline White & Medium & $\mathrm{NG}, \mathrm{P}$ & U.S.A. & $0.062 \pm 0.003$ & $<0.008$ & $<0.008$ & $0.029 \pm 0.002$ & $0.06 \pm 0.003$ & $0.10 \pm 0.001$ & 60 \\
\hline White & Long & $\mathrm{NG}, \mathrm{P}$ & Thailand & $0.066 \pm 0.004$ & $<0.008$ & $<0.008$ & $0.021 \pm 0.002$ & $0.07 \pm 0.004$ & $0.09 \pm 0.006$ & 78 \\
\hline White & Long & $N G, P$ & Thailand & $0.063 \pm 0.002$ & $<0.008$ & $<0.008$ & $0.029 \pm 0.001$ & $0.06 \pm 0.002$ & $0.10 \pm 0.001$ & 60 \\
\hline White & Long & $\mathrm{G}, \mathrm{P}$ & Thailand & $0.070 \pm 0.003$ & $<0.008$ & $<0.008$ & $0.027 \pm 0.002$ & $0.07 \pm 0.003$ & $0.09 \pm 0.004$ & 78 \\
\hline White & $\begin{array}{l}\text { Long } \\
\text { (karijira) }\end{array}$ & NG, P & Bangladesh & $0.024 \pm 0.003$ & $<0.008$ & $<0.008$ & $0.015 \pm 0.001$ & $0.02 \pm 0.003$ & $0.04 \pm 0.001$ & 50 \\
\hline White & $\begin{array}{l}\text { Long } \\
\text { (karijira) }\end{array}$ & NG, P & Bangladesh & $0.023 \pm 0.001$ & $<0.008$ & $<0.008$ & $0.014 \pm 0.001$ & $0.02 \pm 0.001$ & $0.05 \pm 0.003$ & 40 \\
\hline White & $\begin{array}{l}\text { Long } \\
\text { (basmati) }\end{array}$ & $\mathrm{NG}, \mathrm{P}$ & Pakistan & $0.029 \pm 0.003$ & $<0.008$ & $<0.008$ & $0.035 \pm 0.003$ & $0.03 \pm 0.003$ & $0.08 \pm 0.003$ & 38 \\
\hline Violet-black & Short & G, NP & Japan & $0.146 \pm 0.006$ & $<0.008$ & $<0.008$ & $0.012 \pm 0.001$ & $0.15 \pm 0.006$ & $0.14 \pm 0.005$ & 107 \\
\hline Violet-black & Short & G, NP & Japan & $0.275 \pm 0.011$ & $0.027 \pm 0.002$ & $<0.008$ & $0.049 \pm 0.002$ & $0.30 \pm 0.013$ & $0.42 \pm 0.008$ & 71 \\
\hline Violet-black & Short & $\mathrm{G}, \mathrm{NP}$ & Japan & $0.105 \pm 0.004$ & $<0.008$ & $<0.008$ & $<0.008$ & $0.11 \pm 0.004$ & $0.13 \pm 0.010$ & 84 \\
\hline Violet-black & Short & $\mathrm{G}, \mathrm{NP}$ & Japan & $0.120 \pm 0.003$ & $<0.008$ & $<0.008$ & $0.011 \pm 0.001$ & $0.12 \pm 0.003$ & $0.14 \pm 0.008$ & 86 \\
\hline Red & Short & $\mathrm{G}, \mathrm{NP}$ & Japan & $0.166 \pm 0.005$ & $0.010 \pm 0.002$ & $<0.008$ & $0.016 \pm 0.002$ & $0.18 \pm 0.006$ & $0.16 \pm 0.005$ & 113 \\
\hline Red & Short & G, NP & Japan & $0.118 \pm 0.005$ & $0.008 \pm 0.002$ & $<0.008$ & $0.010 \pm 0.000$ & $0.13 \pm 0.004$ & $0.14 \pm 0.009$ & 93 \\
\hline Green & Short & $\mathrm{G}, \mathrm{NP}$ & Japan & $0.086 \pm 0.001$ & $<0.008$ & $<0.008$ & $0.009 \pm 0.001$ & $0.09 \pm 0.001$ & $0.11 \pm 0.002$ & 82 \\
\hline
\end{tabular}

Mean \pm SD (3 determinations)

* G: glutinous, NG: non-glutinous

** NP: not polished (brown) rice, P: polished rice

\# Inorganic As was calculated as the sum of As(III) and As(V). 
(LOD) and the limit of quantification (LOQ) were 0.012 $\mathrm{mg} / \mathrm{kg}$ and $0.04 \mathrm{mg} / \mathrm{kg}$, calculated as 3 times and 10 times the standard deviation of blank tests, respectively.

\section{Extraction and speciation of $A s$}

As we have already reported, partial digestion with diluted nitric acid is a simple extraction method with sufficient efficiency for As speciation. In this study, extraction efficiency was compared at $80^{\circ} \mathrm{C}$ as used in the previous studies ${ }^{11), 12)}$ and at $100^{\circ} \mathrm{C}$. White glutinous rice rather than non-glutinous rice as used in the preceding paper was investigated as both polished and unpolished rice. The extraction efficiency from violetblack glutinous rice (unpolished) and jasmine rice (polished) was also investigated .

Concentrations of total As in glutinous rice and the certified reference material (NIST1568a) are given in Table 2. Extraction efficiency from the certified reference material (NIST1568a) was $94 \%$ and $97 \%$ at $80^{\circ} \mathrm{C}$ and $100^{\circ} \mathrm{C}$, respectively, and these values were considered to be approximately equal. The extraction efficiency from polished glutinous rice was $83 \%$ and $90 \%$ at $80^{\circ} \mathrm{C}$ and $100^{\circ} \mathrm{C}$, respectively, so the difference was small. However, the difference in the efficiency between the two temperatures was large (14-20\%) for unpolished glutinous rice and jasmine rice. Thus, the extraction efficiency at $80^{\circ} \mathrm{C}$ depended on the variety of rice and/or the type of rice (polished or unpolished). At $100^{\circ} \mathrm{C}$, on the other hand, the extraction efficiency was over $90 \%$ for all samples tested, which was sufficient.

The results of As speciation in glutinous brown rice and NIST1568a are shown in Table 3. The concentrations of inorganic As obtained in NIST1568a were 0.084 and $0.091 \mathrm{mg} / \mathrm{kg}$ at $80^{\circ} \mathrm{C}$ and $100^{\circ} \mathrm{C}$, respectively. Interestingly, $\mathrm{As}(\mathrm{V})$ was decreased at $100^{\circ} \mathrm{C}$, though As(III) was increased. The difference in total inorganic As concentration was less than 10\%. In the case of glutinous rice, on the other hand, extracted inorganic As at $100^{\circ} \mathrm{C}$ was significantly higher than that at $80^{\circ} \mathrm{C}$. Based on the results, it was considered that extraction at $100^{\circ} \mathrm{C}$ could be applicable to many types of rice samples. The LOD and the LOQ of each species in this method were $0.002 \mathrm{mg} / \mathrm{kg}$ and $0.008 \mathrm{mg} / \mathrm{kg}$, respectively, calculated as 3 times and 10 times the standard deviation of 10 determinations.

\section{Determination of total and inorganic As in several varieties of rice}

Total and inorganic As were determined for several varieties of rice. The results are given in Table 4 . Total and inorganic As concentrations were $0.04-0.54 \mathrm{mg} / \mathrm{kg}$ and $0.02-0.41 \mathrm{mg} / \mathrm{kg}$, respectively, and content ratios of inorganic As to total As were more than 56\% and $60 \%$ in short and medium grain white rice, respectively. In long grain white rice, except basmati and karijira, the content ratio was $60-78 \%$, being higher than that found in a previous study ${ }^{8}$, but similar to that of rice in Thailand ${ }^{15)}$. In colored short grain rice, the concentration of inorganic As was $0.09-0.30 \mathrm{mg} / \mathrm{kg}$, and the con- tent ratio of inorganic As to total As was 71-113\%. Total and inorganic As were not related to the color of rice. The content ratio of inorganic As in rice was much higher than that in fish and seaweed. Consequently, the inorganic As content in commercial rice represents a potential health risk. In the As speciation of rice samples, partial digestion with nitric acid at $100^{\circ} \mathrm{C}$ seems to be applicable to many varieties of rice.

\section{References}

1) Wendy, A. P., Stephen, A. B., Raymond, S. H. Y. Pharmacokinetics, metabolism, and carcinogenicity of arsenic. Rev. Environ. Contam. Toxicol., 169, 165-214 (2001).

2) International Agency for Research on Cancer (IARC). An Updating of IARC Monographs Volumes 1 to 42, Supplement 7 (1987).

3) Schoof, R. A., Yost, L. J., Eickhoff, J., Crecelius, E. A., Cragin, D. W., Meacher, D. M., Menzel, D. B. A market basket survey of inorganic arsenic in food. Food Chem. Toxicol., 37, 839-846 (1999).

4) Tao, S. S.-H., Bolger, P. M. Dietary arsenic intakes in the United States: FDA total diet study, September 1991December 1996. Food Addit. Contam., 16, 465-472 (1998).

5) Patindol, J., Flowers, A., Kuo, M.-I, Wang, Y.-J., Gealy, D. Comparison of physicochemical properties and starch structure of red rice and cultivated rice. J. Agric. Food Chem., 54, 2712-2718 (2006).

6) Campbell, M. J., Demesmay, C., Ollé, M. Determination of total arsenic concentrations in biological matrices by inductively coupled plasma mass spectrometry. J. Anal. At. Spectrum., 9, 1379-1384 (1994).

7) Larsen, E. H., Stürup, S. Carbon-enhanced inductively coupled plasma mass spectrometric detection of arsenic and selenium and its application to arsenic speciation. J. Anal. At. Spectrum., 9, 1099-1105 (1994).

8) Heitkemper, D. T., Vela, N. P., Stewart,K. R., Westphalb, C. S. Determination of total and speciated arsenic in rice by ion chromatography and inductively coupled plasma mass spectrometry. J. Anal. At. Spectrom., 16, 299-306 (2001).

9) Abedin, M. J., Cresser, M. S., Meharg, A, A., Feldmann, J., Cotter-Howells, J. Arsenic accumulation and metabolism in rice (Oryza sativa L.). Environ. Sci. Technol., 36, 962-968 (2002).

10) Narukawa,T., Inagaki, K., Kuroiwa, T., Chiba, K. The extraction and speciation of arsenic in rice flour by HPLC-ICP-MS. Talanta, 77, 427-432 (2008).

11) Nagaoka, M.H., Nishimura, T., Matsuda,R., Maitani, T. Evaluation of a nitric acid-based partial-digestion method for selective determination of inorganic arsenic in rice. J. Food Hyg. Soc. Japan, 49, 95-99 (2008).

12) Nagaoka, M. H., Hanaoka, K., Usui, M., Nishimura, T., Maitani, T. Nitric acid-based partial-digestion method for selective determination of inorganic arsenic in hijiki and application to soaked hijiki. J. Food Hyg. Soc. Japan, 49, 88-94 (2008).

13) D'Amato, M., Forte, G., Caroli, S. Identification and quantification of major species of arsenic in rice. J. AOAC Int., 87, 238-243 (2004).

14) Vanhaecke, F., Vanhoe, H., Dams, R. The use of internal standards in ICP-MS. Talanta, 39, 737-742 (1992).

15) Williams, P. N., Price, A. H., Raab, A., Hossain, S. A., Feldmann, J., Meharg, A. A. Variation in arsenic speciation and concentration in paddy rice related to dietary exposure. Environ. Sci. Technol., 39, 5531-5540 (2005). 